\title{
Effect of the Mandatory Community Midwifery Service on Maternal Health Care Utilization in Nigeria
}

\author{
Fadare R. I. ${ }^{1}$, Akpor O. A. ${ }^{1, ~ *}$, Oyetunde M. O. ${ }^{2}$ \\ ${ }^{1}$ Department of Nursing, College of Medicine and Health Sciences, Afe Babalola University, Ado-Ekiti, Ekiti State, Nigeria \\ ${ }^{2}$ Department of Nursing, University of Ibadan, Oyo State, Nigeria
}

\author{
Email address: \\ akporoa@abuad.edu.ng (Akpor O. A.)
}

\section{To cite this article:}

Fadare R. I., Akpor O. A., Oyetunde M. O.. Effect of the Mandatory Community Midwifery Service on Maternal Health Care Utilization in Nigeria. American Journal of Nursing Science. Vol. 4, No. 4, 2015, pp. 238-246. doi: 10.11648/j.ajns.20150404.23

\begin{abstract}
The unacceptably high maternal mortality in Nigeria led the Nursing and Midwifery Council of Nigeria to introduce the basic midwifery training with the view of producing skilled personnel to provide midwifery services. Built into the programme is the one-year mandatory community service. The one-year mandatory community service in an intervention aimed at ensuring the availability of midwives (skilled attendants) to provide maternal care in the communities and thus encourage women to access care at the health centre. The study investigated the variation in the levels of utilization of maternal healthcare before and after the inception of the one year mandatory midwives' community service by assessing the perceptions of the Midwives regarding the impact of the mandatory service on the utilization of maternal care services. The General System Theory and the Logic Model were the theoretical models used in this study. The research was conducted in three selected local government areas (LGAs) out of the eighteen (18) LGAs in Ondo State. The time-series type of non-controlled experimental design was the research design used for the study. Records of maternal health care attendance from the selected health facilities from July 2002 to July 2010 were assessed to generate data for the study. The study population comprised the midwives who had participated in the mandatory service in the three selected communities where the three primary health care centres are located. Multistage sampling technique was adopted to select three Local Government Areas (LGAs) from where data was collected. All midwives that have served or are still serving in the selected PHCs were purposely involved, a total of 50 in number. In-depth interview guide and format for recording data from records were used in the study. The interview guide was divided into two sections. Section A, was a checklist was used to explore the participants' opinions on the mandatory community service and Section B was a questionnaire to assess the midwives experience, opinions and challenges. Lastly, a format/checklist was developed to record data from records (antenatal care attendance, deliveries and postnatal care attendance between July 2002 and July 2011). Data from the study was analyzed using both descriptive and inferential statistics utilizing the Statistical Package for the Social Sciences (SPSS) Correlation coefficient was used. The result obtained from the study indicated that there was no significant difference in the levels of utilization of maternal care services before and after the inception of the mandatory community service except for the slight increase in antenatal care utilization. The majority of the midwives claimed that their presence had increased the patronage of maternal care services. However this subjective data was not justified by the statistics obtained. The midwives also highlighted their challenges as well as the way forward.
\end{abstract}

Keyword: Midwives, Maternal Care, Mandatory Community Midwifery Services

\section{Introduction}

Maternal mortality is the most extreme consequence of poor maternal health. Maternal health related complications (complications of pregnancy and childbirth) are the leading cause of disability and death among women of reproductive age (15-49 years) in developing countries. The problem of maternal mortality worldwide can be pictured by imaging a jumbo jet with 274 women aboard gashing into the seas every four hours day-in-day-out, 365 days of the year [1].

Globally, the life time risk of maternal death is 1 in 75 . In the developed countries it is indicated to be 1 in 2500 and 1 in 13 in West Africa. Access to maternity services is grossly deficient, only $65 \%$ of women in developing countries receive antenatal care $63 \%$ in Africa and Asia, and $73 \%$ in Latin America and the Caribbean. In developed countries $97 \%$ of women receive antenatal care. According to 
available statistics, the maternal mortality ratio in Nigeria is currently estimated of 800 maternal deaths per 100,000 live births in 2000, of the estimated 529,000 maternal deaths that occur globally every year, Nigeria contributes approximately $10 \%$, although its population size is only about $2 \%$ of the global population figure. Approximately 52,000 maternal deaths occur yearly due to complications of pregnancy/childbirth, with estimated 37,000 mothers dying annually from pregnancy related causes, Nigeria has the second highest material mortality burden of the world [1, $2]$.

Also, according to Indexmundi (2015), Nigeria maternal mortality rate was 630 deaths/100,000 live births in 2010 [3]. Every single day, Nigeria loses about 2,300 under-five year olds and 145 women of child bearing age. Thus, Nigeria is documented as the second largest contributor to the underfive and maternal mortality rate in the world [4].

Sarkar [5] (2009), observed that maternal health related complication is one of the most prime women's health problems of the world's public health and its consequences are still the leading causes of death, disease and disability among women of reproductive age in developing countries. This directly contributes to high perinatal (newborn) mortality. He also stated that progress of maternal health care services is needed to reduce the high maternal and newborn mortality. The progress means the activities that constitute maternal health care including ante-natal care (ANC), delivery care and postnatal care.

According to The Nigeria Demographic Health Survey [6], health care that a mother receives during pregnancy, at the time of delivery and soon after delivery is important for the survival and wellbeing of both the mother and her child. In order to evaluate the progress of maternal health care services, various indicators are available. The indicators are helpful to follow the coverage of obstetric care and to identify problems within the health care system. WHO [7], recommended a number of indicators to monitor the effect of health care programs on maternal mortality. These indicators can measure the provision of services e.g. the number of essential obstetric care facilities per 500,000 populations, the maternal mortality ratio and proportion of death of women of reproductive age or service utilization such as proportion of births attended by a skilled health worker, antenatal care attendance, delivery care and postnatal care.

In Nigeria, approximately 52,000 maternal deaths occur yearly due to complications of pregnancy/childbirth, the nation accounts for $10 \%$ of global estimate of maternal mortality [2]. In 2015, Nigeria accounts for $13 \%$ global maternal mortality rates, with an estimated 36,000 women dying in pregnancy or at child birth each year and teenage mothers accounts for at least 5500 of these deaths [8]. Due to the declining state of the Nigeria women's health, the Nursing and Midwifery Council of Nigeria (NMCN) reintroduced the basic midwifery training programme in 2003 so as to sustain and augment government initiatives in improving the health status of Nigerian women. The programme is one of the government's initiatives designed to ensure that there is availability of skilled attendants at every birth in the primary health care levels with a view of improving maternal health and consequently reducing maternal mortality.

The Basic Midwifery Programme aims at preparing competent, skilled and versatile midwifery practitioners who are capable of providing high level care to individuals and expectant families in primary health care settings, health clinics and communities in order to reduce maternal and infant morbidity and mortality. The training programme started in Ondo State in 2003 and the first set of midwives graduated in March, 2006.

Despite Government's intervention to introduce the oneyear mandatory community service as a strategy to ensure availability of midwives in the communities, a study by the World Bank officials [9], revealed that women were not patronizing the health facilities for maternal care and that one woman was dying from pregnancy/ childbirth related illness in 16 minutes in Ondo State. It was also found that eightyfour percent $(84 \%)$ of pregnant women were not accessing health care. One of the major problematic areas identified was lack of nursing/midwifery personnel. Moreover it was observed that there is no information available on the effect of these midwives who have been consistently posted for the one year mandatory service in the communities. The study was therefore aimed at assessing the perceptions of the Midwives regarding the impact of the mandatory service on the utilization of maternal care services.

\section{Theoretical Framework}

The General System Theory [10], and the Logic Model [11], was the theoretical models used in this study (Fig. 1). The general system theory has an underlying assumption that the whole is greater than the sum of its parts. A system consists of two or more connected component of subsystem that form an organized whole and that interact with each other to achieve desired goals. A health care facility is a social system of interdependent members (components) possessing two fundamental system features; structures or organization and function or interaction. An input-processoutput feedback model is commonly used to depict the structural relationship of a system. This model illustrate that all systems have inputs or resources that when processed help the system achieve its goals or output. The feedback system theory provides a framework that offers a logical way to integrate all of the factors that influence a social system functioning and link the system together in a meaningful whole.

A logic model [11], is used typically to depict the input, processes and outcomes associated with an organization and its programs. The model can be very useful when designing outcomes- based evaluations of programs. Logic model is best to use to depict major recurring items in the organization or program rather than one-time items so that the program would continue to produce the results desired for clients and the community. These are materials that the program takes in 
and then processed to produce results desired by the program or organization. Types of inputs are people, money, equipment, facility, training, people's ideas etc. A process is used to manipulate and arrange items to produce results desired by the program or organization. Logic models are usually concerned with the major recurring processes associated with producing desired results e.g. midwives offering family planning services, skilled care at deliveries, health education, counseling and management of emergency obstetric conditions, which will eventually enhance the desired results. The outputs are usually the tangible results (outcomes and impact or the ultimate of the major processes in the organization.

In the context of this study, a revision and application of the GST and LM pose viable and highly useful bases. General system theory [10], has its main elements as input, through put (process) and output/feedback loop. Similarly the
Logic Model's [11], components include input (program activities); process (service delivery) output (immediate result; outcome, impact). Designing the basic midwifery programme, training the midwives and equipping them with necessary knowledge, involving them in the one year community service, mandating the midwives to live within the community during the service year, remuneration and equipping them with a midwifery kit each are all inputs.

Service delivery includes all the services that the midwives are expected to offer in the communities such as family planning, deliveries antenatal care, health education home visits, postnatal care etcetera. These yield results which are categorized as immediate, outcome or impact. The impact in the context of this study is improved maternal health utilization (increased antenatal clinic attendance, increased deliveries and increased postnatal clinic attendance).

\section{INPUT}

\section{SERVICE DE LIVERY}

\section{ULTMATE RESULTS, OUTCOME, MPACTS}

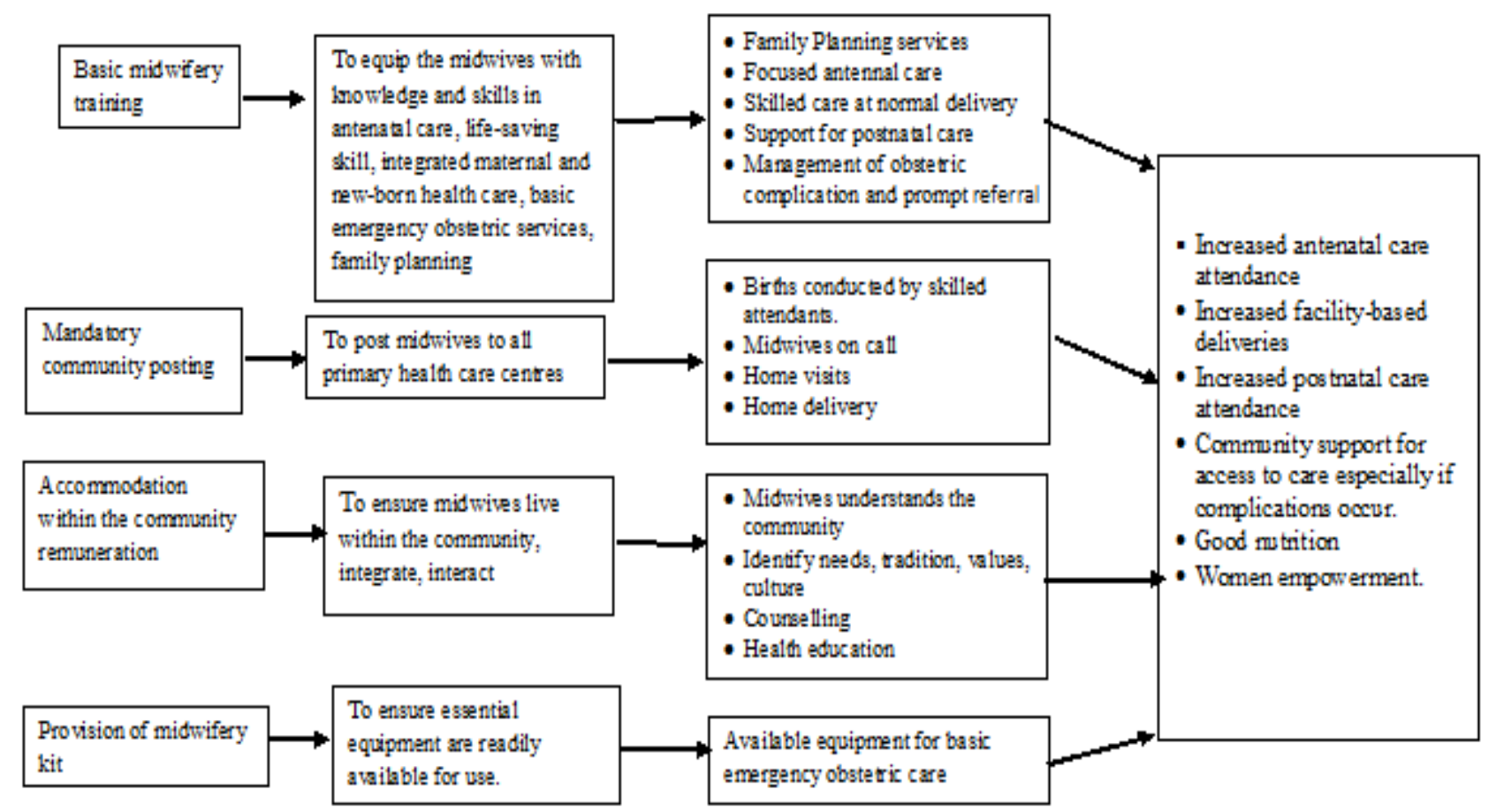

Fig. 1. Modified Logic Model for Impact Mandatory Community Service on Maternal Mortality and Morbidity [Adapted from general System Theory (1998) and Logic Models in Encyclopedia of Evaluation, (2005).

\section{Materials and Methods}

The research was conducted in three selected local government areas (LGAs) out of the eighteen (18) LGAs in Ondo State. The time-series type of non-controlled experimental design was the research design used for the study. Records of maternal health care attendance from the selected health facilities from July 2002 to July 2011 were assessed to generate data for the study. The study population comprised the midwives who had participated in the mandatory service in the three selected communities where the three primary health care centres are located (where records of maternal health care attendance were assessed). Multistage sampling technique was adopted to select three Local Government Areas (LGAs) from where data was collected. The three LGAs were selected by randomization through balloting for the study. In all, three PHCs were selected for the study and the three communities where the PHCs are located were also used. All midwives that have served or are still serving in the selected PHCs were purposely involved, a total of 50 in number. All the 50 midwives responded adequately. In-depth interview guide and format for recording data from records were used in the study. 
The interview guide was divided into two sections. Section A, was a checklist that sought to explore the participants' opinions on the mandatory community service and Section B was a questionnaire to assess the midwives experience, opinions and challenges. Lastly, a format/checklist was developed to record data from records (antenatal care attendance, deliveries and postnatal care attendance between July 2002 and July 2011). Prior to the commencement of the study, the researcher obtained an introductory letter from the Nursing Department to the study settings for permission. A copy of the research proposal was submitted to the Research Review Committee of the Ondo State Ministry of Health and ethical approval was obtained to conduct the study in the State. Written and verbal informed consent was sought and obtained from participants before administration of the questionnaire. Participation was made voluntary without coercion, manipulation or undue inducement. The participants were told that they could freely withdraw at any point during the study process. Participants were told that all information obtained from them will be treated with utmost confidentiality. Both primary and secondary data were used. Research assistants were trained to enter the communities for data collection. Both the researcher and the trained assistants administered questionnaire to the participants.

Permission was obtained from the heads of the PHC in each community to administer the questionnaire. The questionnaires were retrieved from the participants immediately after completion. The secondary data was collected by the researcher from records of the selected health centers in the selected wards. The data covered the period between July 2002 and July 2011. Data from the study was analyzed using both descriptive and inferential statistics utilizing the Statistical Package for the Social Sciences (SPSS) Correlation coefficient was used. All hypotheses were tested using the paired test at 0.05 level of significance. Independent test was utilized because it tests differences between the means of two independent groups, that is, data recorded before and after the inception of the mandatory community service. Measures of relationship was done using Pearson's Product moment correlation coefficient " $r$ " to compute correlation co efficiency between inception of mandatory community service and outcome on utilization of maternal health care. Descriptive statistics was used to provide answers to research questions.

\section{Results}

\section{Analysis of the midwives' experience and challenges}

Table 1. Distribution of midwives $(N=50)$.

\begin{tabular}{lll}
\hline Year of service & Frequency & Percentage (\%) \\
\hline $2006-2007$ & 15 & 30 \\
$2007-2008$ & 10 & 20 \\
$2008-2009$ & 9 & 18 \\
$2009-2010$ & 4 & 8 \\
$2010-2011$ & 12 & 24 \\
TOTAL & 50 & 100 \\
\hline
\end{tabular}

Table 1 shows the distribution of the midwives based on their various years of service. As shown in the Table, a total of 50 midwives served between 2006 and 2011. The highest number of midwives (15) served between 2006-2007 while the lowest number (4) served between 2009 and 2010.

With respect to the characteristics of the health facilities where the midwives served distribution by level of care, a total of $45(90 \%)$ of the facilities were primary level while 5 $(10 \%)$ were secondary levels, with none as tertiary. Regarding the type of facility, majority 47 (94\%) of the facilities offered both In-patient and Out-patient care. Almost all 49 (98\%) of the facilities rendered 24-hour services and they all have delivery services, while 47 (94\%) also attend to antenatal care (Fig. 2). All the participants' responses on whether the attendance level had increased since she started working in the facility were in the affirmative.

Table 2. Characteristics of health facilities where the midwives served $(N=50)$.

\begin{tabular}{|c|c|c|}
\hline Health facility characteristics & Frequency & Percentage (\%) \\
\hline \multicolumn{3}{|l|}{ Level of care } \\
\hline Primary & 45 & 90 \\
\hline Secondary & 5 & 10 \\
\hline Tertiary & 0 & 0 \\
\hline \multicolumn{3}{|l|}{ Type of facility $(\mathrm{N}=50)$} \\
\hline In-patient & 2 & 4 \\
\hline Out patient & 1 & 2 \\
\hline Both & 47 & 94 \\
\hline \multicolumn{3}{|c|}{ Are service offered 24 hours $(\mathrm{N}=50)$} \\
\hline Yes & 49 & 98 \\
\hline No & 1 & 2 \\
\hline \multicolumn{3}{|l|}{ Delivery service offered } \\
\hline Yes & 50 & 100 \\
\hline No & 0 & 0 \\
\hline \multicolumn{3}{|l|}{ Antenatal service offered } \\
\hline Yes & 47 & 94 \\
\hline No & 3 & 6 \\
\hline \multicolumn{3}{|l|}{ Post abortion care service offered } \\
\hline Yes & 46 & 92 \\
\hline No & 4 & 8 \\
\hline \multicolumn{3}{|l|}{ Postnatal care service offered } \\
\hline Yes & 46 & 92 \\
\hline No & 4 & 6 \\
\hline \multicolumn{3}{|l|}{ Family planning service offered } \\
\hline Yes & 45 & 90 \\
\hline No & 5 & 10 \\
\hline \multicolumn{3}{|c|}{ Treatment of mirror ailments service offered } \\
\hline Yes & 48 & 96 \\
\hline No & 2 & 4 \\
\hline \multicolumn{3}{|c|}{ Voluntary counseling and testing for HIV service offered } \\
\hline Yes & 35 & 70 \\
\hline No & 15 & 30 \\
\hline \multicolumn{3}{|l|}{ Immunization service offered } \\
\hline Yes & 15 & 30 \\
\hline No & 35 & 70 \\
\hline
\end{tabular}

The participants' responses on what was responsible for the increase in attendance level, the majority of them revealed that community mobilization/outreach and free services and quality care by midwives were responsible. Only a single participant indicated that home visit and free health programme for pregnant women and children was responsible for the increase in attendance level (Table 3). A 
total of 46 participants indicated that there has been an started working in the facilities (Fig. 3). increase in the number of deliveries since the midwives

Table 3. Perceived reasons for increase attendance level in clinics and number of deliveries since the midwives started working in the facility ( $N=50)$.

\begin{tabular}{lll}
\hline Responses & Frequency & Percentage \\
\hline Perceived reasons for increase in clinic attendance & & 24 \\
Community mobilization/outreach & 12 & 24 \\
Free services and quality care by midwives & 12 & 14 \\
Good services and patient nurse relationship & 7 & 10 \\
Health education & 5 & 6 \\
Total nurse care & 3 & 20 \\
Availability of new midwives posted to the area & 10 & 2 \\
Home visit and free health programme for pregnant women and children & 1 & 100 \\
TOTAL & 50 & 92 \\
Increase in number of deliveries & & 8 \\
Yes & 46 & 100 \\
No & 4 & 50 \\
\hline
\end{tabular}

As shown in Table 4, the distribution of responses on whether the number of deliveries had increased since the midwives started working in the facility, 46 (92\%) claimed that it has increased while $4(8 \%)$ claimed that it has not increased. On the midwives' perceived contributory factors to the increase in the number of deliveries, $19(38 \%)$ midwives attributed it to free health care and good services while $13(26 \%)$ participants attributed it to regular home visits and cordial relationship with patients (Table 4). On the challenges impeding increase in the number of deliveries, almost all the participants indicated no response while two (4\%) of them expressed the challenge as too much work because of lack of equipment (Table 4).

Table 4. Factors responsible for the increase in the number of deliveries and challenges impeding increase in number of deliveries.

\begin{tabular}{lll}
\hline Responses & Frequency & Percentage (\%) \\
\hline Factors responsible for the increase in the number of deliveries & & 38 \\
Free health care and good services & 19 & 26 \\
Regular home visits and cordial relationship with patients & 13 & 16 \\
Competent midwives & 8 & 16 \\
Quality antenatal care and good health plan & 8 & 4 \\
No response & 2 & 100 \\
TOTAL & 50 & 4 \\
Challenges impeding increase in level of delivery & 2 & 96 \\
We work too much because of lack of equipment & 48 & 100 \\
No response & & 50 \\
TOTAL & & 100 \\
\hline
\end{tabular}

Table 5. Messages provided by the midwives during home visits and challenges that hindered midwives from going on home visits $(N=50)$.

\begin{tabular}{lll}
\hline Response & Frequency & Percentage \\
\hline Health promotion and practices & 6 & 12 \\
Creating awareness/community mobilization & 14 & 28 \\
Proper nutrition and health education on child delivery & 4 & 8 \\
Family planning, ante-natal care, delivery in health centre & 6 & 12 \\
Exclusive breastfeeding male circumcision, post-natal exercise, immunization. & 4 & 8 \\
Treatment of mirror advents & 6 & 12 \\
No response & 10 & 20 \\
TOTAL & 50 & 100 \\
Challenges that hindered the midwives from going on home visits & & 10 \\
No enough time & 5 & 6 \\
No motivation & 3 & 84 \\
No response & 42 & 100 \\
TOTAL & 50 & 88 \\
Home visit as part of midwives routine activity & & 12 \\
Yes & 44 & 100 \\
No & 6 & \\
TOTAL & 50 & \\
\hline
\end{tabular}

Table 5 shows participants responses regarding the key messages provided in sensitizing the community. As shown in the Table $6,(12 \%)$ of the midwives claimed they provided message on health promotion practices while $14(28 \%)$ of 
them indicated the creation of awareness and mobilization (Table 5). Only a few of the participants mentioned lack of adequate time for sensitization (10\%) and motivation $(6 \%)$ as challenges that hindered the midwives from going on home visits. The majority of the participants 48 (88\%) mentioned routine home visits as part of their routine activity (Table 5).

When investigating the services provided by the midwives during home visits, Table 6 illustrate the distribution of the various services offered by the participants during home visits, education on exclusive breastfeeding family planning
(28\%), health education on regular antenatal care attendance and delivery at the centre and clean environment (28\%) and health education on personal hygiene, proper nutrition and clean environment $(26 \%)$ were the dominant responses (Table 6). The participants' impact on the community revealed, $12(24 \%)$ of the midwives mentioning increase antenatal care attendance and facility deliveries while 11 (22\%) stating improved attitude of people towards facility utilization and willingness to deliver in the health centre (Table 6).

Table 6. Services provided and impacts of the participants during home visits.

\begin{tabular}{|c|c|c|}
\hline Responses & Frequency & Percentage $(\%)$ \\
\hline \multicolumn{3}{|l|}{ Services provided during home visits } \\
\hline Health education on regular antenatal care attendance and delivery at the centre & 14 & 28 \\
\hline Health education on personal hygiene, proper nutrition and clean environment & 13 & 26 \\
\hline Education exclusive breastfeeding family planning and clean environment. & 14 & 28 \\
\hline Health talks on malaria prevention & 2 & 4 \\
\hline Talks on danger signs of pregnancy & 3 & 6 \\
\hline \multicolumn{3}{|l|}{ Impacts of the home visits } \\
\hline Health promotion & 4 & 8 \\
\hline Increased patronage & 5 & 10 \\
\hline Change of attitude of people towards personal hygiene & 9 & 18 \\
\hline Increase in ANC attendance and facility delivery & 12 & 24 \\
\hline Contributed toward reduction in maternal and child mortality & 6 & 12 \\
\hline $\begin{array}{l}\text { Improved attitude of patient towards hospital attendance and willingness to deliver } \\
\text { at the centre }\end{array}$ & 11 & 22 \\
\hline TOTAL & 50 & 100 \\
\hline
\end{tabular}

The analysis of the participants' challenges in the communities revealed poor transportation/lack of functional ambulance services for prompt referral and uncooperative attitudes of patients/relatives as the major challenges. On suggestions for improving the mandatory community service, the majority of the participants suggested provision of equipment and drugs to the centres, provision of basic amenities to midwives and training of more midwives (Table 7).

Table 7. Analysis of participants' challenges and suggestions for improving the scheme.

\begin{tabular}{lll}
\hline Response & Frequency & Percentage (\%) \\
\hline Participants' challenges & & 10 \\
Poor communication network water shortage and poor power supply lack of social amenities & 5 & 10 \\
Insufficient staff/equipment and delay in salary payment & 5 & 26 \\
Poor transportation/lack of functional ambulance services for prompt referral & 13 & 22 \\
Uncooperative attitudes of patients/relatives & 11 & 14 \\
Language barrier/cultural barrier/taboos & 7 & 8 \\
Illiteracy problems & 4 & 10 \\
Over work & 5 & 100 \\
TOTAL & 50 & 2 \\
Suggestions for improvement of the scheme & & 8 \\
Government should improve the standard of living of the people in rural areas & 1 & 4 \\
Regular payment of salary & 4 & 24 \\
Improve road network and electricity supply & 2 & 30 \\
Training of more midwives & 12 & 26 \\
Supply of equipment and drugs to the centres & 15 & 4 \\
Provision of basic amenities to midwives & 13 & 2 \\
Posting of more midwives to the rural areas & 2 \\
Increase the salary/allowance of the midwives & 1 & 100 \\
TOTAL & 50 & \\
\hline
\end{tabular}

Table 8 highlights participants' responses regarding the 
morbidity. As revealed in the Table 8, 20 (40\%) midwives stated that it is a good effort towards reduction of maternal

mortality and morbidity.

Table 8. Participants responses on the relevance of the programme regarding maternal mortality and morbidity.

\begin{tabular}{lll}
\hline Responses & Frequency & Percentage (\%) \\
\hline It is a good effort towards reduction of maternal mortality and morbidity. & 20 & 40 \\
The women know the danger signs and when to seek care in the health centre & 8 & 16 \\
The midwives are always available to attend to emergencies & 10 & 20 \\
It enable women receive good and timely care & 4 & 8 \\
No response & 8 & 16 \\
TOTAL & 50 & 100 \\
\hline
\end{tabular}

Table 9 highlights the relationship between the levels of antenatal attendance and facility deliveries before (2002-

2006) and after (2007-2011) the inception of the mandatory community service.

Table 9. Relationship between antenatal clinic attendance and facility based deliveries before and after the inception of mandatory community service.

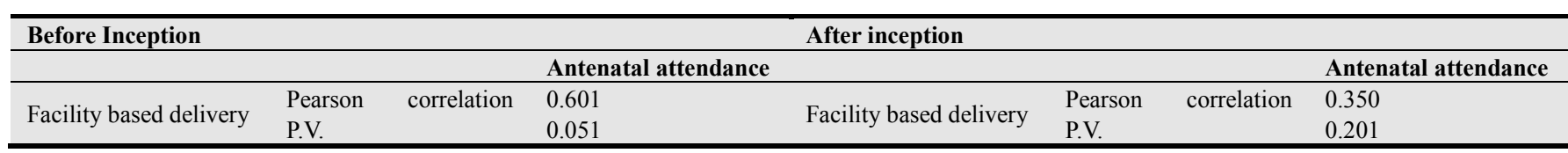

Table 9 shows the relationship between antenatal care attendance and facility based deliveries before and after the inception of the mandatory community service. The level of antenatal clinic attendances and facility based delivery was significantly related. $\mathrm{P} . \mathrm{V}=0.05$ and the relationship is very strong, that is, $r=0.601$. Conversely, the level of antenatal clinic attendances and facility based delivery after the inception was not significantly related, $P . V=0.201>.05$ ( $\mathrm{r}$ $=0.350$ ).
As shown in Table 10, the number of postnatal attendance before and after inception of the mandatory community service was 190.5 and 165.6, respectively. The level of postnatal care attendance before and after the inception of the Mandatory Community Service is not significantly different $(\mathrm{PV}=0.087>0.05)$. This was revealed from the findings that there is no appreciable improvement in the level of postnatal care attendance after introduction of mandatory community service by the midwives.

Table 10. Differences in levels of postnatal care before (2002-2006) and after inception of the mandatory community service.

\begin{tabular}{|c|c|c|c|c|}
\hline & \multicolumn{4}{|l|}{ Group statistics } \\
\hline & Differences & Mean & Std. Deviation & Std. Error Mean \\
\hline \multirow{2}{*}{$\begin{array}{l}\text { Variation in the postnatal clinic attendance before and } \\
\text { after mandatory community service }\end{array}$} & Before Inception & 190.5 & 2.12132 & 1.5 \\
\hline & After Inception & 165.6 & 15.63010 & 6.9899 \\
\hline
\end{tabular}

\section{Discussion}

The distribution based on the years of service showed that midwives were being posted to the Local Government consistently from July 2006 to July 2011. Regarding the characteristics of the health facilities where the midwives served, they were all primary level (PHC) offer both inpatient and out-patient services as well as offer twenty-four hour services. This shows that the midwives were always available to offer services. The data collected for this research also revealed that the type of services rendered by the midwives in these facilities included antenatal care, delivery care, post abortion care, postnatal care, family planning, treatment of minor ailments; voluntary counseling and testing for HIV and immunization.

These findings negate the findings of Babalola and Fatusi [12], that the poor staffing of the health care facilities had made it difficult to guarantee twenty-four hours availability of services. The contributory factors were identified to include free health services, regular home visits and cordial relationships with patients, competent midwives, quality antenatal care and good birth plans. While the challenge identified were gross lack of equipment as stated by the midwives. Mrisho et al., [13], tends to support this statement that lack of equipment and supplies were common complaints reported.

As part of their activities, the midwives mentioned that they conducted community sensitization (82\%) and the messages provided included issues on health promotion and practices, creating awareness and community mobilization, health education on proper nutrition, family planning, antenatal care, and benefit of delivering in the health centre, exclusive breastfeeding, postnatal exercises and care. These were considered the midwives attempts to create awareness on the existence of the facilities and services available as recommended by Dharkal et al., [14], that awareness should be created in the community to motivate pregnant women to attend antenatal care as this would in turn encourage them to seek delivery and postnatal care. Also the majority of the midwives mentioned that they also conducted home visits as one of their routine activities and the various services offered during the visits included health education on personnel hygiene, proper nutrition, need for antenatal care and facility delivery, and family planning, recognition of danger signs in pregnancy as well as prevention of malaria. This tends to further buttress the recommendation of Dharkal et al., [14]. 
As expressed by the midwives, they believed that they had made impact on the community by means of home visits which they believed had contributed to reduction of maternal morbidity and mortality in the community. The major challenges identified by the midwives included poor communication network (poor reception), shortage of clean water and electricity supply, insufficient staff and equipment and delayed salary, poor transportation and lack of functional ambulance for prompt referral, lack of social amenities.

On the relevance of the programme, the participants' stated that the programme is a good effort towards reduction of maternal mortality and morbidity; it has given the women positive knowledge of the danger signs of pregnancy, it makes the midwives available to attend to emergencies and that it enables the women to receive timely care. These opinions however corroborate the Nursing and Midwifery Council of Nigeria's justification for the programme, which is to ensure that skilled personnel provide maternal care services in the communities thereby reduce maternal and infant mortality and morbidity [15].

\section{Conclusion, Recommendations and Limitation}

In this study, a purposive and multistage sampling techniques were used to select three LGAs out of the eighteen (18) LGAs in the State where data were collected. Structured questionnaire was used to study the experience and challenges of the midwives in the communities. Appropriate statistical package (SPSS) was used to analyze the gathered data while descriptive statistics were used to analyze the opinions, experience and challenges.

The result obtained from the study indicated that there was no significant difference in the levels of utilization of maternal care services before and after the inception of the mandatory community service except for the slight increase in antenatal care utilization. The majority of the midwives claimed that their presence had increased the patronage of maternal care services. However this subjective data was not justified by the statistics obtained. The midwives also highlighted their challenges as well as the way forward.

The study found out that there was a slight increase in the levels of utilization of antenatal attendance while not much change had occurred in the use of facility based delivery care as well as postnatal care. Also there was no correlation between the level of antenatal care attendance and facility based deliveries before and after the inception of the mandatory community service. The challenges highlighted include staff shortage, poor means of communication, shortage of clean water and electricity supplies, delayed salaries/allowances, lack of equipment and drugs, poor transportation and lack of functional ambulance for prompt referral, uncooperative attitude of patients and relatives, taboos, illiteracy and overwork.

Based on the finding of the study the following recommendations were made.
- More midwives should be trained and deployed to the communities.

Government should endeavour to make the midwives comfortable in the communities by providing basic amenities for them.

- The salary /allowances of the midwives should be made regular. Rural posting allowance should be approved for midwives.

- Drugs and equipment should be provided so as to make work easier for the midwives.

- Midwives should endeavour to keep accurate record of their services.

- Local government should employ the midwives after the mandatory service so that more midwives will be available in the communities.

The limitation of the study is the purposive and convenient sample of all midwives that have served or are still serving in the three selected PHCs (where records of maternal health care attendance were assessed) and only three Primary Health Care facilities were used out of the eighteen Local Government Areas in the State, hence the results are not generalizable to a larger content.

The findings provided insight on the perceived impact of the one year mandatory community service for the graduates of the Basic Midwifery Training Programme on the utilization of maternal health services. This could provide empirical information upon which regulatory bodies and policy makers can base their decision to continue or stop the programme or re-design the programme and the curriculum. The findings could also influence the State's decision to continue the programme or re-channel the State's resources to other programmes that could better improve maternal health in the State. The research will provide insight into the challenges that the midwives face in the communities such that stakeholders would be able to identify the immediate areas needing high focus. Findings can lead to policy formulation in health field as well as in other research endeavours.

\section{Acknowledgement}

The authors are grateful to all who granted them permission for this study to be conducted and all participants in the study.

\section{References}

[1] World Health Organization Maternal Mortality in 2005; Estimate developed by WHO; UNFPA, UNICEF and the World Bank. Geneva. WHO. 2007.

[2] Shifman, J and Okonofua, F.E. (2007). The state of political priority for safe motherhood in Nigeria. International Journal of Obstetrics and Gynaecology, 114(2): 127-133.

[3] Indexmundi. (2015). Nigeria maternal mortality rate. [Online]. Available from: www.indexmundi.com/nigeria/maternal_mortality_rate.html (Accessed: 30/07/2015). 
[4] UNICEF. (2015). Maternal and child health. [Online]. Available from: www.unicef.org/nigeria/children_1926.html (Accessed: 30/07/2015).

[5] Sarkar, P. (2009). Indicators of maternal health care services: Bangladesh context. Pakistan Journal of Social Sciences, 6(3): 169-172.

[6] National Population Commission (NPC). (2009). Nigeria demographic and health survey, 2008. [Online]. Available from: http://www.unicef.org/nigeria/ng_publications_Nigeria_DHS 2008_Final_Report.pdf (Accessed: 30/07/2015).

[7] World Health Organization. (2005). The world health report: make every mother and child court. Geneva. 2005.

[8] Thisdaylive. (2015). Global maternal mortality rate. [Online]. Available from: www.thisdaylive.com/articles/nigeria/183394 (Accessed: 30/07/2015).

[9] Obadare,O. (2010). Tackling Infant, Maternal Mortality in Ondo State. Sunday Punch, June 25.

[10] Hayajneh, Y. (2007). Management for health care professionals series systems and systems theory. Management for Health Care Professionals Series. [Online]. Available from: http://www.hayajneh.org/a/readings/Systems-Theory.pdf
(Accessed: 30/07/2015).

[11] Kellogg, W.K. (2004). Using Logic Models to Bring Together Planning, Evaluation, and Action Logic Model Development Guide. [Online]. Available from: http://www.smartgivers.org/uploads/logicmodelguidepdf.pdf (Accessed: 30/07/2015).

[12] Babalola, S and Falusi, A. (2009). Determinant of use of Maternal Health Services in Nigeria looking beyond individual and household factors. Biomedical Central, Pregnancy and Childbirth, 9: 43.

[13] Mrisho, M., Obrist, B., Schellenberg, A.J., Haws, R.A., Mushi, A.K., Mshinda, H., Tanner, M and Schellenberg, D. (2009). The use of antenatal and postnatal care: Perspectives and experiences of women and health care providers in Rural Southern Tanzania. Biomedical Central, Pregnancy and Childbirth 9:10.

[14] Dharkal, S., Chapman, G.N., Simkhada, P.P., Teijlingen, E.R., Stephens, J and Raja, A.E. (2007). Utilization of Postnatal Care among Rural Women in Nepal. Biomedical Central Pregnancy and Childbirth, 7:19.

[15] Nursing and Midwifery Council of Nigeria (NMCN). (2004). Draft of Blueprint for Basic Midwifery Education and Practice. 